\title{
Assessment of wave energy variation in the Persian Gulf
}

\author{
B. Kamranzad ${ }^{\text {a }}$, V. Chegini ${ }^{\text {b }}$ and A. Etemad-shahidi ${ }^{\mathrm{c}^{*}}$ \\ ${ }^{a}$ School of Civil Engineering, Iran University of Science and Technology, Narmak, \\ Tehran, Iran, P.O. Box 16765-163, Tel: +9821 77240399, Fax: +9821 77240398, \\ E-mail address: kamranzad@iust.ac.ir \\ ${ }^{\mathrm{b}}$ Ocean Engineering and Technology Research Center, Iranian National Institute for \\ Oceanography, Tehran, Iran, Fax: +98-21-66944869 \\ E-mail address: vahid.chegini@gmail.com \\ ${ }^{\mathrm{c}}$ Griffith School of Engineering, Gold Coast campus \\ GRIFFITH UNIVERSITY QLD 4222 \\ *Corresponding Author, E-mail: a.etemadshahidi@griffith.edu.au
}

\begin{abstract}
Since wave energy has the highest marine energy density in the coastal areas, assessment of its potential is of great importance. Furthermore, long term variation of wave power must be studied to ensure the availability of stable wave energy. In this paper, wave energy potential is assessed along the southern coasts of Iran, the Persian Gulf. For this purpose, SWAN numerical model and ECMWF wind fields were used to produce the time series of wave characteristics over 25 years from 1984 till 2008. Moreover, three points in the western, central and eastern parts of the Persian Gulf were selected and the time series of energy extracted from the modeled waves were evaluated at these points. The results show that there are both seasonal and decadal variations in the wave energy trends in all considered points due to the climate variability. There was a reduction in wave power values from 1990 to 2000 in comparison with the previous and following years. Comparison of wind speed and
\end{abstract}


corresponding wave power variations indicates that a small variation in the wind speed can cause a large variation in the wave power. The seasonal oscillations lead to variation of the wave power from the lowest value in summer to the highest value in winter in all considered stations. In addition, the seasonal trend of wave power changed during the decadal variation of wave power. Directional variations of wave power were also assessed during the decadal variations and the results showed that the dominant direction of wave propagation changed in the period of 1990 to 2000 especially in the western station.

Keywords: wave energy; Persian Gulf; SWAN model; ECMWF wind fields; wave power trend.

\section{Introduction}

Using renewable energy resources is very important in the future due to the fact that fossil fuels are nonrenewable. Wave energy contains the highest energy density among clean and green sources (Leijon et al., 2003). Furthermore, predictability as well as the low visual and environmental impact make the wave energy a valuable renewable energy resource (Iglesias et al., 2009). Therefore, estimation of wave energy potential and usage of its energy is necessary to provide for the energy demand in the countries adjacent to the seas. The total global offshore wave energy potential has been evaluated to be up to $10 \mathrm{TW}$, which is sufficient for world energy demand (Panicker, 1976).

Global wave energy potential was investigated by Arinaga and Cheung (2012) and Cornett (2009). European wave energy resources were also assessed by Pontes (1998). Wave energy assessment has also been carried out regionally in countries with the potential of energy extraction from the ocean waves, such as Spain (Iglesias and 
Carballo, 2010a, 2010b, 2010c), UK (Folley and Whittaker, 2009), Portugal (Mollison and Pontes, 1992; Pontes et al., 2005; Rusu and Guedes Soares, 2009), Sweden (Bernhoff et al., 2006; Waters et al., 2009), US (Beyene and Wilson, 2007; Wilson and Beyene, 2007; Stopa et al., 2011; Lenee-Bluhm et al., 2011; Defne et al., 2009), Argentina (Lanfredi et al., 1992), South Korea (Kim et al., 2011), Taiwan (Chen et al., 2010), Turkey (Akpınar and Kömürcü, 2012) and Australia (Hughes and Heap, 2010). Despite the proximity of Iran to three important seas (Caspian Sea, Persian Gulf and Gulf of Oman) and its long coastlines, there are few studies of the wave energy potential in Iranian Seas. Abbaspour and Rahimi (2011) determined the wave energy in several coastal locations of the Persian Gulf and the Gulf of Oman. Saket and Etemad-Shahidi (2012) also evaluated the wave energy potential in the northern coasts of the Gulf of Oman and determined the locations of nearshore hot spots. As well as determining the wave energy resources, it is necessary to evaluate the variation of wave power in a specified region to account for long-term changes in climate. Tsai et al. (2012) assessed the long term temporal trend of wave energy in Taiwan. They showed that the variations in wave climate consisting of annual, seasonal and decadal variations, lead to the changes in the wave energy converter outputs in long-term. For investigating the long term variations of the wave climate, long-term data is required. Unfortunately, these long-term recorded data are not available in most regions. Therefore, the required data can be obtained from the results of numerical modeling and hindcasted data. In addition to the mentioned investigations in the Iranian Seas, a project was carried out by Iranian National Institute for Oceanography (INIO) and Iran University of Science and Technology (IUST) to estimate the wave energy in all Iranian seas and determine the potential sites for energy extraction from the waves. In that project, a 
global modeling of wave parameters was conducted by authors in the Persian Gulf (Etemad-Shahidi et al., 2011), Gulf of Oman and Caspian Sea using SWAN

(Simulating Waves Nearshore) model. Afterwards, the hot spots were specified and local modeling with higher resolution was performed in the selected sites. Finally, the most proper locations for energy capturing were determined based on the energy amount, depth, distance from the coast and other economical, political and environmental aspects, at each site.

Data obtained from the global wave hindcating in the Persian Gulf was used in this study to assess the temporal variations of the wave energy and to investigate the effect of climatic changes on the wave energy trends. The results can be used for determination of the energy capturing capacity and selecting the proper wave energy converter based on the seasonal, decadal or directional variations.

\section{Study area and data sources}

The study area is the Persian Gulf, a crescent shaped water body formed from the extension of the Indian Ocean. The Persian Gulf is located in the south of Iran and is also adjacent to the countries in the Arabian Peninsula. It is an important area due to the existence of rich resources of oil and gas, as well as transportations and fisheries (Figure 1). Therefore, investigation of marine resources for providing the required energy is very important in this area. The Persian Gulf is a relatively shallow sea and its average depth is about 36 meters (Kämpf and Sadrinasab, 2005).

Estimation of the wave power potential requires long-term wave characteristics data. These long-term data are not commonly available and can be obtained from the numerical modeling. For this purpose, bathymetry and wind field data are necessary. Bathymetry data were obtained from the NOAA's National Geophysical Data Center 
(NGDC) website, including $1 \mathrm{~min}$ (about $1.67 \mathrm{~km}$ ) spatial resolution and wind data used for numerical modeling of the wave characteristics were provided by the European Centre for Medium-Range Weather Forecasts (ECMWF). The ECMWF reanalysis (ERA-40) was used for the years 1985 to 2002 and ECMWF operational dataset was used for the years 2002 to 2008 . Both data sets were interpolated to 0.2 degree grids. These data contain 6 hourly wind components in $10 \mathrm{~m}$ above the sea level, from 1984 to 2008.

Measured wave data from two buoys in 1-hourly intervals were also used for calibration and verification of the numerical modeling. One of these buoys was located in $50.5^{\circ} \mathrm{E}$ and $28.58^{\circ} \mathrm{N}$ near the Boushehr port, Iran (about $46 \mathrm{~km}$ offshore) in a depth of about $28 \mathrm{~m}$ which was deep water while the other buoy was located in $52.55^{\circ} \mathrm{E}$ and $27.51^{\circ} \mathrm{N}$ near the Assalouyeh port (about $2 \mathrm{~km}$ offshore) in depth of about $50 \mathrm{~m}$ which was also deep water (Figure 1).

Statistical characteristics of measured wave datasets used for calibration and verification steps are shown in Table 1 . This table indicates the relative statistical similarity of the wave parameters in both periods. The peak values of significant wave height were used for the calibration period to ensure the appropriate calibration of the model.

\subsection{Numerical modeling}

A third generation numerical model SWAN (Booij et al., 1999) was used for modeling of the wave characteristics in the Persian Gulf. SWAN is a spectral wave model developed for estimation of the wave characteristics in nearshore areas. This model can solve the transport equation (WAMDI group, 1988; Komen et al., 1994) without considering any limitation on the wave energy spectral form (Bolaños- 
Sanchez et al., 2007). SWAN also considers the effective processes for small scale, high resolution applications (generation, dissipation and nonlinear wave-wave interactions) (Ris et al., 1999).

The action balance equation is the basic equation used in the SWAN and for the Cartesian coordinates it is defined as (Ris et al., 1999):

$\frac{\partial}{\partial t} N+\frac{\partial}{\partial x} c_{x} N+\frac{\partial}{\partial y} c_{y} N+\frac{\partial}{\partial \sigma} c_{\sigma} N+\frac{\partial}{\partial \theta} c_{\theta} N=\frac{S}{\sigma}$

in which $N$ represents the action density. It is a function of intrinsic frequency $(\sigma)$, wave direction $(\theta)$, horizontal coordinates $(x$ and $y)$ and the time $(t)$. The first term on the left-hand side indicates the temporal change of $N$ and the next two terms illustrate the propagation of $N$ in geographical $x$ and $y$ space, respectively (in which, $c_{x}$ and $c_{y}$ are the propagation velocities in $x$ and $y$ directions, respectively). The fourth term demonstrates the shifting effect of the relative frequency due to variations in depth and currents (in which, $c_{\sigma}$ shows the propagation velocity in $\sigma$ space). The last term on the left-hand side of the equation represents the depth and current-induced refraction (in which, $c_{\theta}$ shows the propagation velocity in $\theta$ space). The term $S$ on the right-hand side of the equation is a function of $\sigma, \theta, x, y$ and $t$. It consists of effects of the generation by wind, dissipation (by white-capping, depth induced wave breaking and bottom friction) and nonlinear wave-wave interactions (Ris et al., 1999). The model was executed in two dimensional nonstationary mode. It was noted by Moeini and Etemad-Shahidi $(2007,2012)$ that using theory of Komen et al. (1984), wind input parameterization yields more accurate results for prediction of significant wave height. Therefore, Komen et al. (1984) option was used in the simulations. Computational time step was selected as $10 \mathrm{~min}$ and the model outputs were also produced in 0.2 degree (about $20 \mathrm{~km}$ ) resolution in the computational domain with a 
time steps of $3 \mathrm{hr}$. (Figure 1). Other grid sizes (higher resolution) had been checked first and a $0.2^{\circ}$ resolution was found to be the most proper grid size considering a reasonable running time. Wave growth term of Cavaleri and Malanotte (1981) with the proportionality coefficient of 0.0015 was activated in the modeling process.

Dissipation due to whitecapping, breaking and friction were also included firstly with default values and then, were optimized in the calibration process. The quadruplets were also included in the computations with default values.

\section{2. Model validation}

SWAN model was calibrated in order to increase the consistency between measured and modeled wave power rather than only significant wave height. Model calibration was conducted for a one month period from Nov., 1, 1995 to Dec., 1, 1995. Time series of measured and modeled wave characteristics for calibration are shown in

Figure 2.

For quantitative assessment of the calibration results, error indices (Bias, correlation coefficient $(C C)$ and root mean square error $(R M S E)$ ) were calculated according to the Eqs. (2) to (4) and shown in Table 2.

$$
\text { Bias }=\bar{y}-\bar{x}
$$

$C C=\frac{\sum_{i}\left(\left(x_{i}-\bar{x}\right) \times\left(y_{i}-\bar{y}\right)\right)}{\sqrt{\sum_{i}\left(x_{i}-\bar{x}\right)^{2} \sum_{i}\left(y_{i}-\bar{y}\right)^{2}}}$

$R M S E=\sqrt{\frac{\sum_{i}\left(x_{i}-y_{i}\right)^{2}}{n}}$

in which, $x$ and $y$ are the measured and modeled values, respectively and $\bar{x}$ and $\bar{y}$ are their average values, respectively. It must be noted that calibration of the model was 
carried out based on minimization of Bias and RMSE. The rate of whitecapping dissipation was selected as 1.602 E-5 to improve the model outputs. For breaking and friction coefficients, the default values were used.

After calibrating the model coefficients (white-capping, bottom friction and breaking), it was verified to confirm its reliability. For this purpose, time series of wave characteristics were selected for the period of Mar., 8, 1999 to Mar., 31, 1999. For further validation of the model, the measured data in Assalouyeh from Oct., 22, 2007 to Dec., 29, 2007 was utilized. The results of model verification are indicated in Figures 3 and 4 and Table 2. Results shown in Figures 2, 3 and 4 and Table 2 represent that there is an acceptable correlation between the hindcasted and measured values of the wave power. These results also show that as well as the wave power, modeling of significant wave height and peak period was performed well.

\subsection{Wave energy estimation}

Data obtained from the numerical modeling were used for estimation of the wave power potential in the Persian Gulf. Ertekin and Yingfan (1994) presented some methods for estimating the wave power, such as using the observed wave height and period, the significant wave height and period, the observed wind, the Rayleigh wind and observed wind data using Weibull distribution.

Since the most common method for wave energy estimation over long periods used in many studies such as Saket and Etemad-Shahidi (2012), Henfridsson et al. (2007) and Abbaspour and Rahimi (2011) is wave power calculation using significant wave height and period, this method was utilized also in this study. The wave energy density is calculated from the Eq. (5) (Hughes and Heap, 2010).

$$
E=\frac{1}{16} \rho g H_{s}^{2}
$$


In which $\rho$ is the water density, $g$ is the gravitational acceleration and $H_{s}$ is the significant wave height (in meter). The wave power is defined as:

$P=E C_{g}=E C n$

where $C$ shows the wave speed and $n$ is the ratio of the wave group speed to wave speed. $C$ is equal to wave length divided by the wave period $(T)$ and is equal to $g T^{2} / 2 \pi$ in deep water. The approximate value of $n$ is equal to 0.5 in deep water. Therefore, the wave power is calculated as follow.

$P=\frac{1}{16} \rho g H_{S}^{2} \times \frac{g T}{2 \pi} \times 0.5 \approx 0.49 H_{S}^{2} T$

The real sea states include a large number of regular waves. Therefore, the mixture of different amplitudes, frequencies and directions is described using a variance spectral density function. The wave power per unit width of the irregular waves in deep water can be obtained by (Abbaspour and Rahimi, 2011):

$P=\approx 0.49 H_{S}^{2} T_{e}$

in which $T_{e}$ is known as the energy period. When peak period $\left(T_{p}\right)$ is available, $T_{e}$ can be equal to $T_{p}$ multiplied by a factor that is equal to 0.9 if the standard JONSWAP spectrum with a peak enhancement factor of $\gamma=0.33$ is assumed (Abbaspour and Rahimi, 2011). The calibration of the model was done based on the error minimization of $H^{2} T$ (instead of $H$ or $T$ ), to achieve higher accuracy for modeled wave power value. Therefore time series of this parameter were shown in figures 2 to 4 to compare the model and measured $H^{2} T$.

In this study, time series of significant wave height and peak period were also obtained from the modeling results and wave energy was calculated in each point of the output grid $(0.2$ degree $\simeq 20 \mathrm{~km})$ for the whole 25 -years modeling period (19842008). The average wave energy for the total period of 25 -years simulation is 
displayed in Figure 5 showing the highest values of wave power in the central part of the Persian Gulf. There is an area in the middle of the Persian and near the Iranian coasts known as Ra's-e-Motaf. This region is known as Iran's Bermuda triangle due to its stormy conditions and high waves caused sinking lots of ships. Figure 5 also shows that the lowest wave power value is obtained in the Strait of Hormuz in the eastern part of the Persian Gulf.

\section{Results and Discussion}

According to figure 5, the wave energy regime in the western, middle and eastern parts of the Persian Gulf is different. This variation can be also seen in northern and southern parts of the Persian Gulf. Since the northern parts near the Iranian coasts are more important in this study, only variations in western, middle and eastern parts are assessed. For this purpose, three locations from the model outputs (that cover whole the Persian Gulf with $0.2^{\circ}$ resolution) were selected to represent variations along the northern coast of the Persian Gulf. These stations were located in the western, central and eastern parts of the Persian Gulf labeled by W, M and E letters, respectively

(Figure 1). The location and depth of the stations are given in Table 3. As seen, all of them are located in deep water. Time series of wave characteristics were extracted in the selected stations from the wave hindcasting results and wave power was calculated for each time step, using Eq. 8. The annual average of wave power for each point was obtained and plotted in Figure 6. This figure shows a sharp drop in annual average values of wave power during the years 1990 to 2000 for stations $\mathrm{W}$ and $\mathrm{M}$ as well as variation in annual wave power in all years. It seems that variations of annual wave energy were decreased during 1990-2000 period at the selected stations. This may be due to the decadal variations of the climate as discussed by Tsai et al. (2012). 
In addition, annual energy of station $\mathrm{M}$ is generally higher than those of other stations. This is in line with obtained results from Figure 5 which represents the higher values of the wave energy in the central Persian Gulf.

The variation of the annual average of the wind speed was also investigated (Figure 7). Figure 7 shows the wind speed variation during the 25 -years wave modeling in the selected locations. Comparison of the Figures 6 and 7 illustrates that the variations of average wind speeds are less than that of average wave power. For quantitative evaluation of these variations, average values of wind speed and wave power were calculated during 1984-1989, 1990-2000 and 2000 -2008 periods. The average wind speed in the station $\mathrm{W}$ for the mentioned periods were $6.14,5.76$ and $5.71 \mathrm{~m} / \mathrm{s}$, respectively while wave power values were $2.02,0.47$ and $1.5 \mathrm{~kW} / \mathrm{m}$, respectively in this station. This means that a variation of about $6 \%$ in wind speed leads to a variation of about $77 \%$ in wave power.

Average values of the wind speed in station $\mathrm{M}$ for the considered periods were also $5.98,4.53$ and $5.66 \mathrm{~m} / \mathrm{s}$, respectively; while average values of the wave power were $3.93,0.39$ and $2.73 \mathrm{~kW} / \mathrm{m}$, respectively. This means that a variation of about $24 \%$ in wind speed value causes to a variation of about $90 \%$ in wave power amount. For the station E, the average wind speed for three periods were $3.71,3.66$ and $4.48 \mathrm{~m} / \mathrm{s}$, respectively and wave powers were $0.48,0.18$ and $0.7 \mathrm{~kW} / \mathrm{m}$, respectively. It can be concluded that a variation of about $1.3 \%$ in wind speed leads to a variation of about $63 \%$ in wave power there. Comparison of the above results shows that a small variation in the wind speed can cause a high variation of the wave power. The dominant wind direction in the Persian Gulf blows from the northwest (Thoppil and Hogan, 2010) and according to Figure 1, the northwest fetch length of the station $\mathrm{M}$ is longer than others'. Because of the long fetch length in station $\mathrm{M}$, the ratio of wind 
speed variation to wave power variation is less than those of stations $\mathrm{W}$ and $\mathrm{E}$. The effect of wind speed reduction on wave power in station $M$ is less than those of other stations, because there is enough fetch length for waves to be developed.

To assess the seasonal variations of the wave power, seasonal averages of the hindcasted 25-years wave power were obtained in the selected stations (Figure 8).

Figure 8 shows that in all stations, the highest and lowest values of wave energy occur in winter and summer, respectively. Figure 8 also indicates that average wave energy decreases from spring to summer and then increases continuously in autumn and winter and decreases again in spring. This figure also shows that station $\mathrm{M}$ has the highest wave power among the other stations in each season. Seasonal variations of wave power for different years are plotted in Figures 9 to 11 for stations W, M and E, respectively. Similar to Figure 6, Figures 9 to 11 illustrate decrease of the seasonal average wave power during 1990-2000 period. It can be concluded from these figures that there is less seasonal variation of wave power during 1990 -2000 period in all stations, i.e. the difference between seasonal averaged wave powers reduces as do its values in this period. Furthermore, unlike the results shown in Figure 8, the peak seasonal wave energy is observed in summer, autumn and spring instead of in winter, in some years during 1990-2000 period.

Determining the dominant wave direction is necessary in design of a wave energy converter. Since the seasonal trend of the wave power was changed during 19902000 period, the wave direction variation was also investigated during this period. For this purpose, wave directions in the three selected locations were obtained to show how wave directions vary with decadal variations. Power roses of stations $\mathrm{W}, \mathrm{M}$ and E are shown in Figures 12 to 14, respectively. Figure 12 shows that as well as the wave power value, the dominant wave direction was also changed during 1990-2000 
period. This figure indicates the high frequency of low wave powers during this period and there is less wind blowing from NW and the direction of prevalent waves (winds) has changed from NW to SE.

Similarly, Figures 13 and 14 also illustrate the high frequency of low wave powers in stations $\mathrm{M}$ and E, respectively. Figures 13 and 14 show the same dominant wave direction as those of the previous and following years for the second period (NW in Figure 13 and SW in Figure 14). According to Figure 13, the wave direction in 19902000 is more distributed than that of other years and the wind blowing from NW are not so strong. Figure 14 also indicates that the dominant wave direction also changes from $\mathrm{W}-\mathrm{SW}$ in the first period to $\mathrm{SW}$ in the second and last periods and the winds blowing from SW are not so strong in the second period.

For quantitative comparison of the wave directions and frequencies, wave power distributions in station $M$ are represented in Tables 4, 5 and 6 for periods of 1984 to 1989, 1990 to 2000 and 2001 to 2008, respectively. Comparison of these tables shows that the low wave power frequency is increased during 1990 to 2000 in comparison with other periods, and the frequency of waves with power higher than $10 \mathrm{~kW} / \mathrm{m}$ is negligible during 1990-2000 period. The dominant direction of the wave distribution is NW in all three periods. However, there are also low frequencies of wave power in all directions for the first and third periods. The frequency of the wave power is negligible in N-NE to E-SE directions during this period. These results show that the variation of the wind speed not only affects the seasonal and decadal variations of the wave power, but also changes the directional distribution and the frequency of the wave power.

\section{Summary and Conclusions}


In this research, long term wave hindcasted data obtained from a numerical hindcasting using SWAN model were utilized for evaluation of the wave power potential in the Persian Gulf. After calibration and verification of the model, wave power values were calculated in each time step. Three points were selected in the western, central and eastern parts of the Persian Gulf for assessing the temporal trends of wave power and wave energy. Time series of annual and seasonal wave powers were plotted and the results showed that there are seasonal and annual variations in wave power in all stations. Seasonal assessment showed that generally, there is higher wave power in winter in comparison with other seasons. In addition, a decadal reduction in wave power was observed during 1990-2000 period. A comparison between the average wind speed and average wave power was conducted and the results showed that a small variation in wind speed value causes a large variation in the wave power.

Furthermore, annual and seasonal variations of wave power decreased during the years 1990 to 2000. Seasonal trend of wave power was also changed during this period (1990 to 2000) and the highest values of wave power were observed in summer and autumn seasons in some years. For the assessment of wave power variation during decades, results of wave modeling was divided into three periods (1984 to 1989, 1990 to 2000 and 2001 to 2008) and wave directions were also investigated. The results indicated that the wave direction and frequency distribution of wave power were changed during 1990-2000 period. This can be due to the climate change and its effects on the winds and consequently, wave power. Studies should be carried out over a longer period to investigate whether these variations are cyclic or periodic and repeat in certain periods.

\section{Acknowledgement}


The authors are thankful to the Islamic Republic of Iran Meteorological Organization (IRIMO) for providing the buoy measurements. We would also like to thank the SWAN groups at Delft University of Technology for making the model freely available. We also thank Ian Johnson for editing the manuscript. 


\section{References}

Abbaspour, M., Rahimi, R., 2011. Iran atlas of offshore renewable energies. Renew. Energy. 36, 388-398.

Akpınar, A., Kömürcü, M.İ., 2012. Wave energy potential along the south-east coasts of the Black Sea. Energy. 42, 289-302.

Arinaga, R.A., Cheung, K.F., 2012. Atlas of global wave energy from 10 years of reanalysis and hindcast data. Renew. Energy. 39, 49-64.

Bernhoff, H., Sjostedt, E., Leijon, M., 2006. Wave energy resources in sheltered sea areas: a case study of the Baltic Sea. Renew. Energy. 31, 2164-2170.

Beyene, A., Wilson, J.H., 2007. Digital mapping of California wave energy resource. International J. Energy Res. 31, 1156-1168.

Bolaños-Sanchez, R., Sanchez-Arcilla, A., Cateura, J., 2007. Evaluation of two atmospheric models for wind-wave modelling in the NW Mediterranean. J. Mar. Sys. $65,336-353$.

Booij, N., Ris, R.C., Holthuijsen, L.H., 1999. A third-generation wave model for coastal regions. 1. Model Description and validation. J. Geophys. Res. 104, 76497666.

Cavaleri, L., Malanotte-Rizzoli, P., 1981. Wind wave prediction in shallow water:Theory and applications. J. Geophys. Res. 86, No. C11, 10,961-10,973.

Chen, F., Lu, S.M., Tseng, K.T., Lee, S.C., Wang, E., 2010. Assessment of renewable energy reserves in Taiwan. Renew. and Sustain. Energy Rev. 14, 2511-2528.

Cornett, A.M., 2009. A global wave energy resource assessment. Sea Technology. 50, 59-64.

Defne, Z., Haas, K.A., Fritz, H.M., 2009. Wave power potential along the Atlantic coast of the southeastern USA. Renew. Energy. 34, 2197-2205.

Etemad-Shahidi, A., Kamranzad, B., Chegini, V., 2011. Wave energy estimation in the Persian Gulf. Proceedings of the International Conference on Environmental Pollution and Remediation, Canada. paper no. 223.

Ertekin, R.C., Yingfan, X., 1994. Preliminary assessment of the wave-energy resource using observed wave and wind data. Energy. 19, 729-738.

Folley, M., Whittaker, T.J.T., 2009. Analysis of the nearshore wave energy resource. Renew. Energy. 34, 1709-1715.

Henfridsson, U., Neimane, V., Strand, K., Kapper, R., Bernhoff, H., Danielsson, O., Leijon, M., Sundberg, J., Thorburn, K., Ericsson, E., Bergman, K., 2007. Wave 
energy potential in the Baltic Sea and the Danish part of the North Sea, with reflections on the Skagerrak. Renew. Energy. 32, 2069-2084.

Hughes, M.G., Heap, A.D., 2010. National-scale wave energy resource assessment for Australia. Renew. Energy. 35, 1783-1791.

Iglesias, G., Carballo, R., 2010. Wave energy and nearshore hot spots: The case of the SE Bay of Biscay. Renew. Energy. 35, 2490-2500.

Iglesias, G., Carballo, R., 2010. Wave energy resource in the Estaca de Bares area (Spain). Renew. Energy. 35, 1574-1584.

Iglesias, G., Carballo, R., 2010. Wave power for La Isla Bonita. Energy. 35, 50135021.

Iglesias, G., López, M., Carballo, R., Castro, A., Fraguela, J.A., Frigaard, P., 2009. Wave energy potential in Galicia (NW Spain). Renew. Energy. 34, 2323-2333.

Kämpf, J., Sadrinasab, M., 2005. The circulation of the Persian Gulf: a numerical study. Ocean Science Dis. 2, 129-164.

Kim, G., Jeong, W.M., Lee, K.S., Jun, K., Lee, M.E., 2011. Offshore and nearshore wave energy assessment around the Korean Peninsula. Energy. 36, 1460-1469.

Komen, G.J., Cavaleri, L., Donelan, M., Hasselmann, K., Hasselmann, S., Janssen, P.A.E.M., 1994. Dynamics and modeling of ocean waves, Cambridge University Press.

Komen, G.J., Hasselmann, S., Hasselmann, K., 1984. On the existence of a fully developed wind sea spectrum. J. Phys. Oceanogr. 14, 1271-1285.

Lanfredi, N.W., Pousa, J.L., Mazio, C.A., Dragani, W.C., 1992. Wave-power potential along the coast of the province of Buenos Aires, Argentina. Energy. 17, 9971006.

Leijon, M., Bernhoff, H., Berg, M., Ågren, O., 2003. Economical considerations of renewable electric energy production-especially development of wave energy. Renew. Energy. 8, 1201-1209.

Lenee-Bluhm, P., Paasch, R., Özkan-Haller, H.T., 2011. Characterizing the wave energy resource of the US Pacific Northwest. Renew. Energy. 36, 2106-2119.

Moeini, M.H., Etemad-Shahidi, A., 2007. Application of two numerical models for wave hindcasting in Lake Erie. Appl. Ocean Res. 29, 137-145.

Moeini, M.H., Etemad-Shahidi, A., Chegini, V. and Rahmani, I. 2012. Wave data assimilation using a hybrid approach in the Persian Gulf, Ocean Dynamics, 62, 785797

Mollison, D., Pontes, M.T., 1992. Assessing the Portuguese wave-power resource. Energy. 17, 255-268. 
Panicker, N.N., 1976. Power resource potential of ocean surface wave, in: The wave and salinity gradient workshop. Newark, Delaware, USA. 1-48.

Pontes, M.T., 1998. Assessing the European wave energy resource. J. Offshore Mechanics and Arctic Engineering. 120, 226-231.

Pontes, M.T, Aguiar, R., Pires, H.O., 2005. A nearshore wave energy atlas for Portugal. J. Offshore Mechanics and Arctic Engineering. 127, 249-255.

Ris, R.C., Holthuijsen, L.H., Booij, N., 1999. A third-generation wave model for coastal regions 2. Verification. J. Geophys. Res. 104, 7667-7681.

Rusu, E., Guedes Soares, C., 2009. Numerical modelling to estimate the spatial distribution of the wave energy in the Portuguese nearshore. Renew. Energy. 34, $1501-1516$.

Saket, A., Etemad-Shahid, A., 2012. Wave energy potential along the northern coasts of the Gulf of Oman. Renew. Energy. 40, 90-97.

Stopa, J.E., Cheung, K.F., Chen, Y.L., 2011. Assessment of wave energy resources in Hawaii. Renew. Energy. 36, 554-567.

Thoppil, P.G., Hogan, P.J., 2010. Persian Gulf response to a wintertime shamal wind event. J. Deep-Sea Res. I. 57, 946-955.

Tsai, C.P., Hwang, C.H., Hwa, C., Cheng, H.Y., 2012. Study on the wave climate variation to the renewable wave energy assessment. Renew. Energy. 38, 50-61.

WAMDI group, 1988. The WAM model-a third generation ocean wave prediction model. J. Phys. Oceanogr. 18, 1775-1810.

Waters, R., EngstrÖm, J., Isberg, J., Leijon, M., 2009. Wave climate off the Swedish west coast. Renew. Energy. 34, 1600-1606.

Wilson, J.H., Beyene, A., 2007. California wave energy resource evaluation. J. Coast. Res. 23, 679-690.

Wu, J., 1982. Wind stress coefficients over sea surface from breeze to hurricane. J. Geophys. Res. 87, 9704-9706. 


\section{Figures caption}

Fig. 1. Study area, computational grid and location of selected stations in the Persian Gulf

Fig. 2. Time series of modeled and measured parameters, calibration period, in

Boushehr: (a) significant wave height, (b) Peak period and (c) $H^{2} T$

Fig. 3. Time series of modeled and measured parameters, verification period, in Boushehr: (a) significant wave height, (b) Peak period and (c) $H^{2} T$

Fig. 4. Time series of modeled and measured parameters, verification period, in Assalouyeh: (a) significant wave height, (b) Peak period and (c) $H^{2} T$

Fig. 5. Wave power $(\mathrm{kW} / \mathrm{m})$ distribution in the Persian Gulf

Fig. 6. Time series of the annual average of the wave power for three stations

Fig. 7. Time series of the annual average of the ECMWF wind speed

Fig. 8. Seasonal averages of wave power

Fig. 9. Seasonal variation of wave power, station $\mathrm{W}$

Fig. 10. Seasonal variation of wave power, station M

Fig. 11. Seasonal variation of wave power, station $\mathrm{E}$

Fig. 12. Power roses for three different periods, station $\mathrm{W}$

Fig. 13. Power roses for three different periods, station $\mathrm{M}$

Fig. 14. Power roses for three different periods, station E 


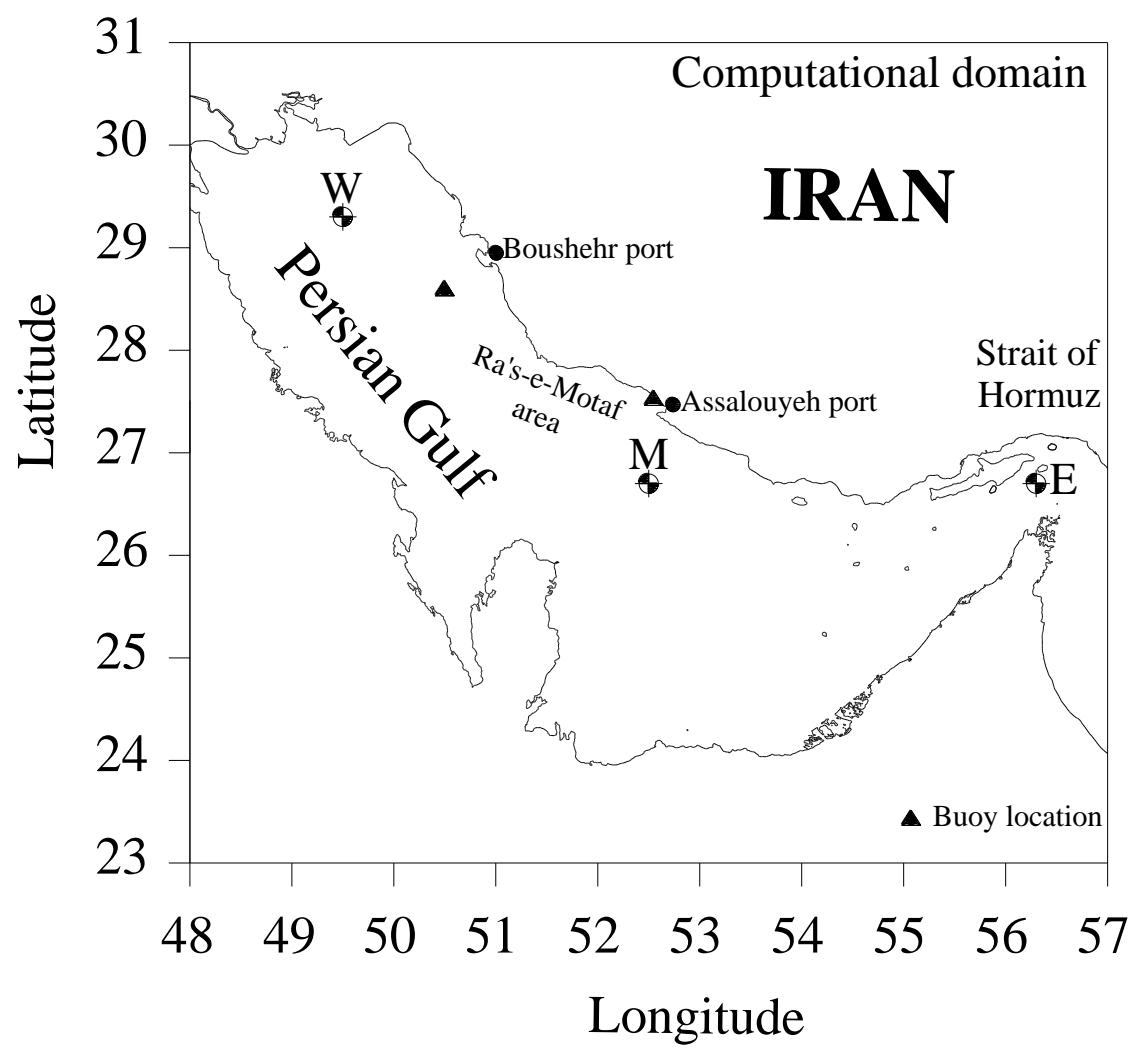

Fig. 1. Study area, computational grid and location of selected stations in the Persian Gulf 

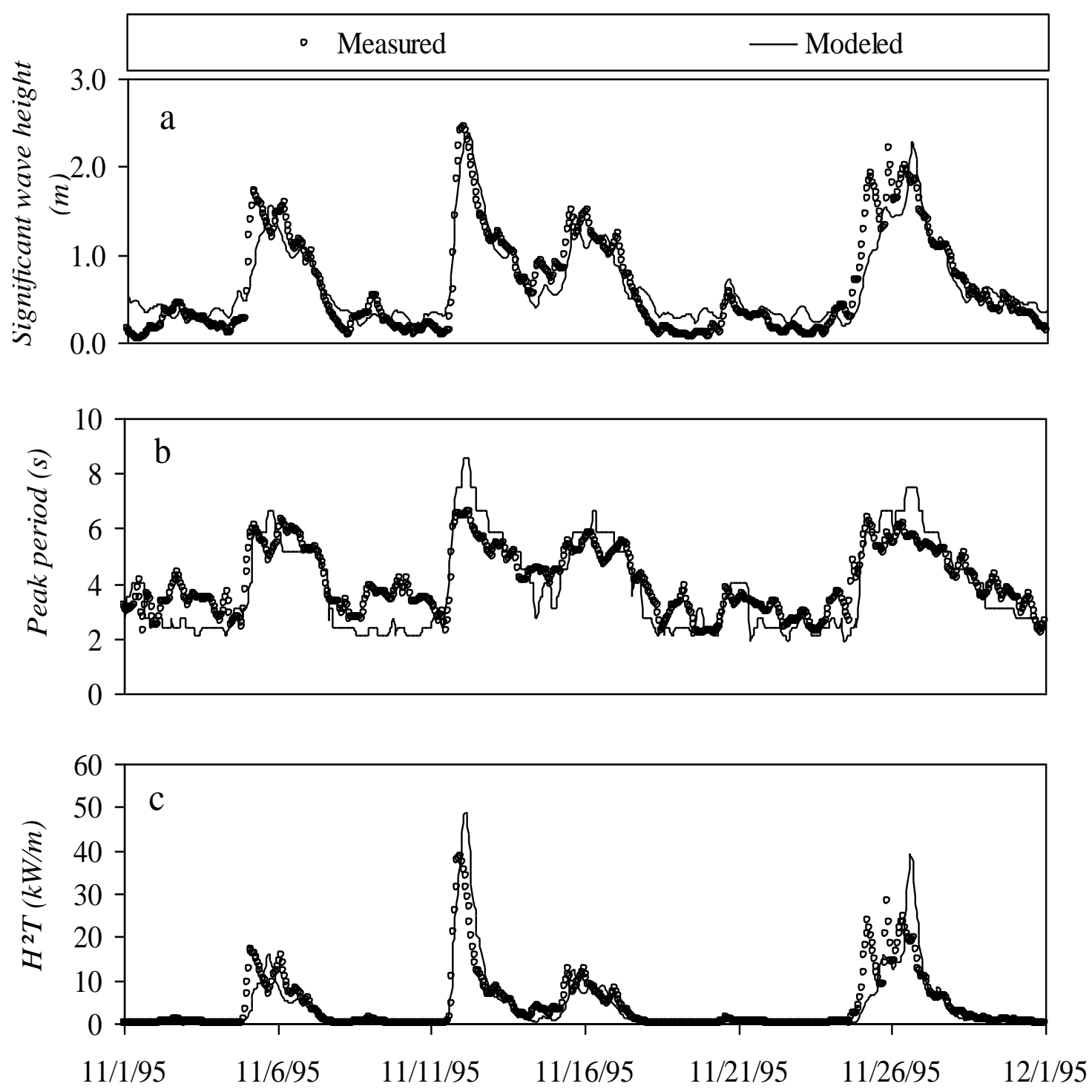

Fig. 2. Time series of modeled and measured parameters, calibration period, in Boushehr: (a) significant wave height, (b) Peak period and (c) $H^{2} T$ 

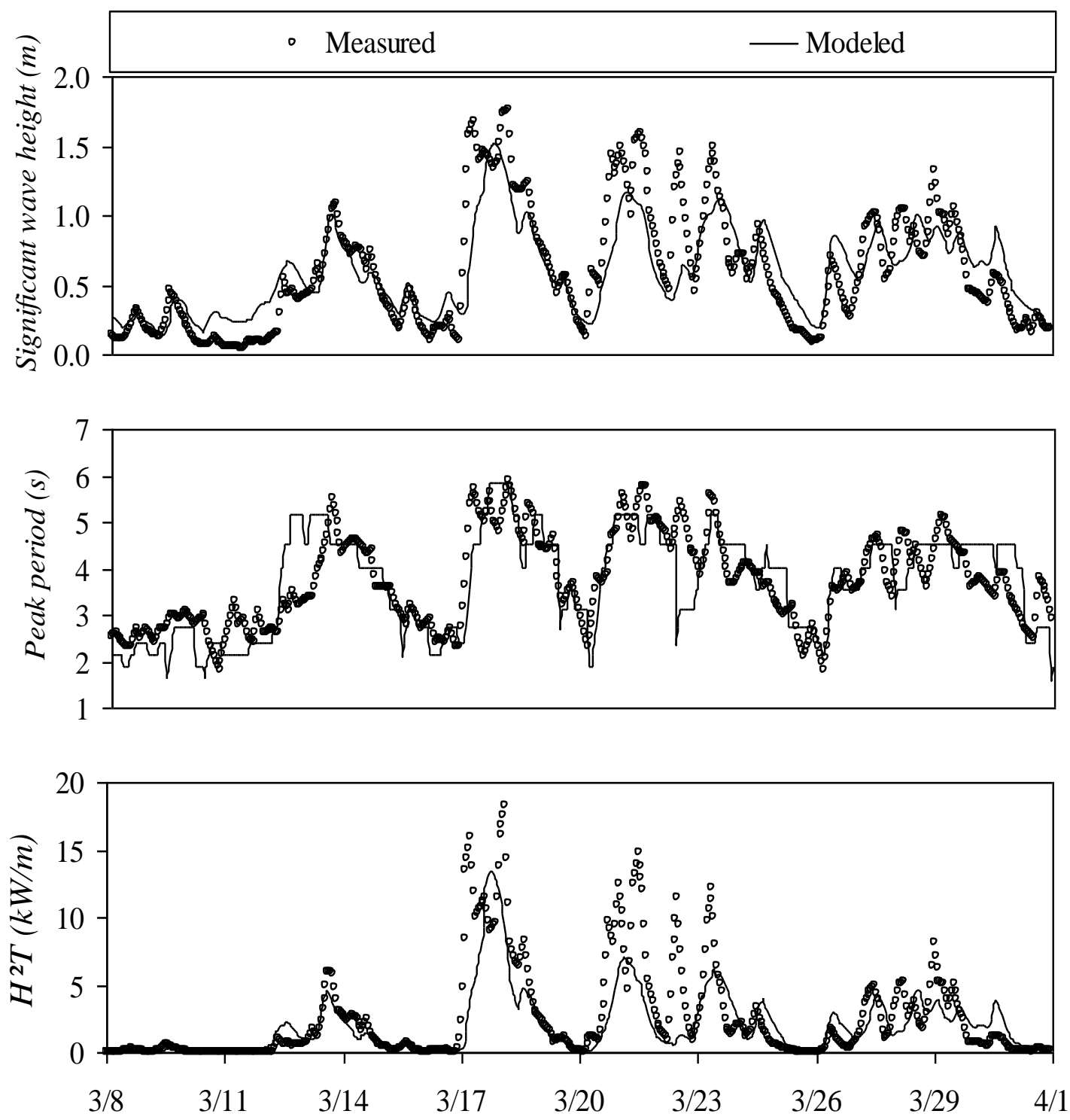

Fig. 3. Time series of modeled and measured parameters, verification period, in Boushehr: (a) significant wave height, (b) Peak period and (c) $H^{2} T$ 

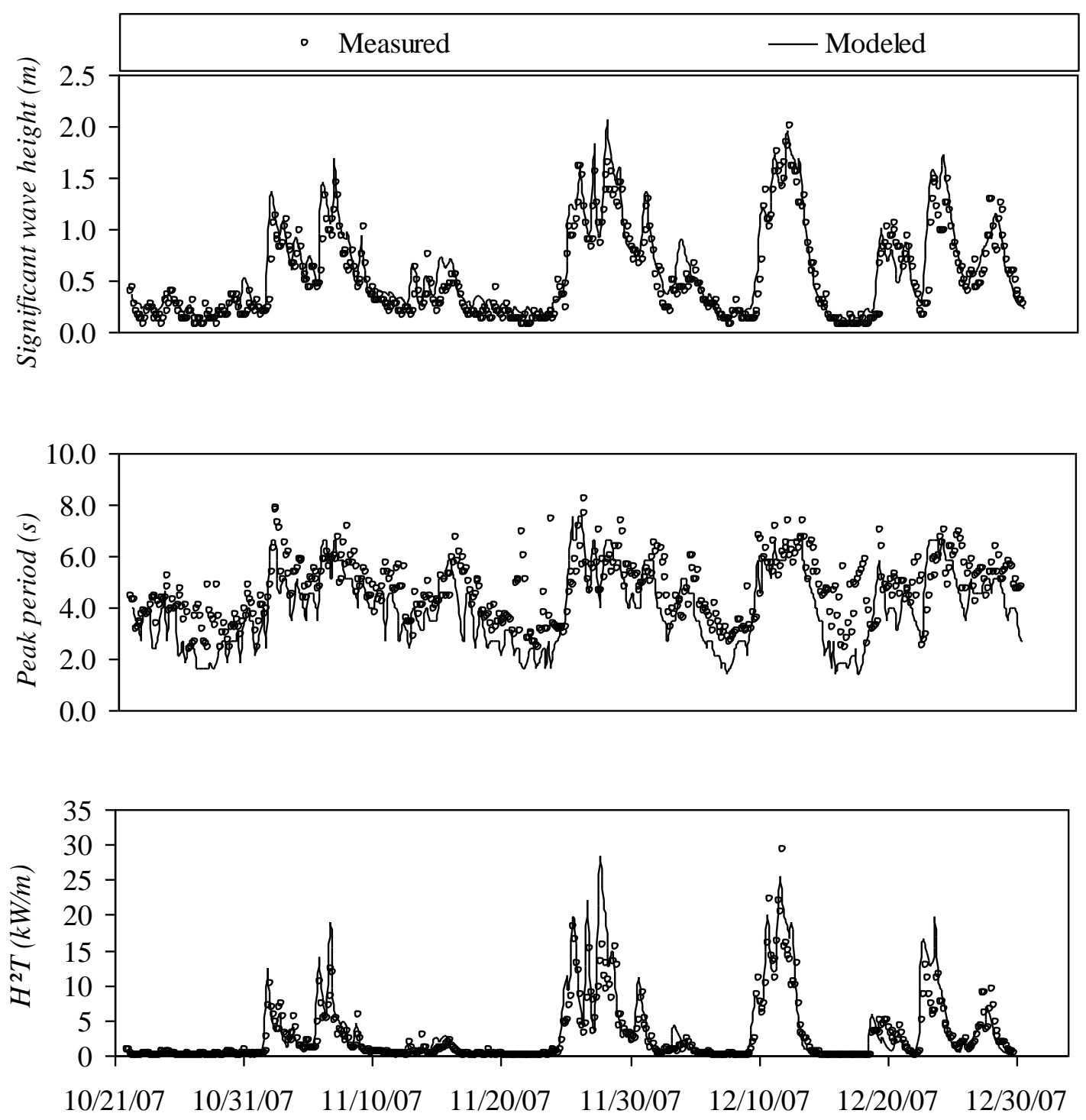

Fig. 4. Time series of modeled and measured parameters, verification period, in Assalouyeh: (a) significant wave height, (b) Peak period and (c) $H^{2} T$ 


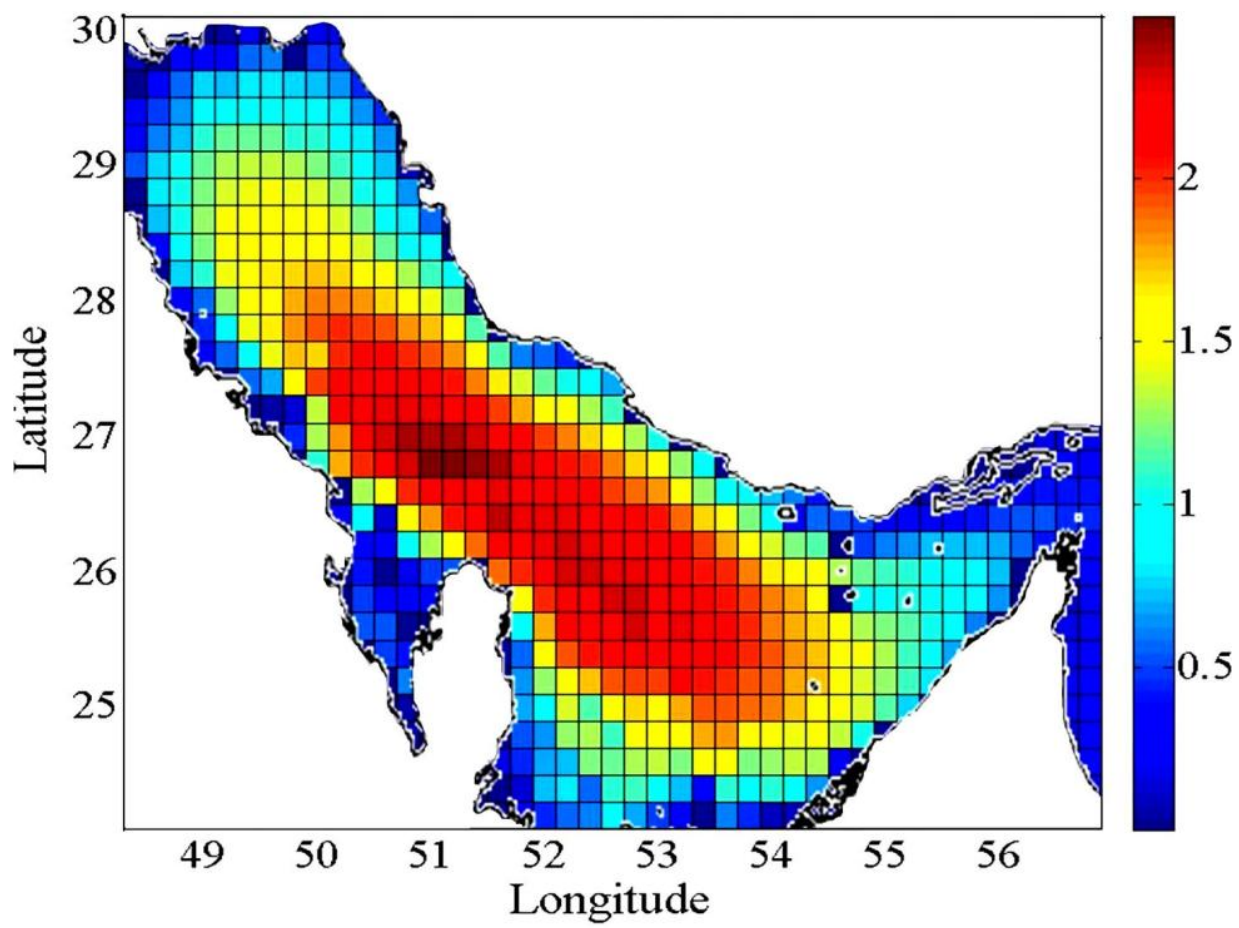

Fig. 5. Wave power $(\mathrm{kW} / \mathrm{m})$ distribution in the Persian Gulf 


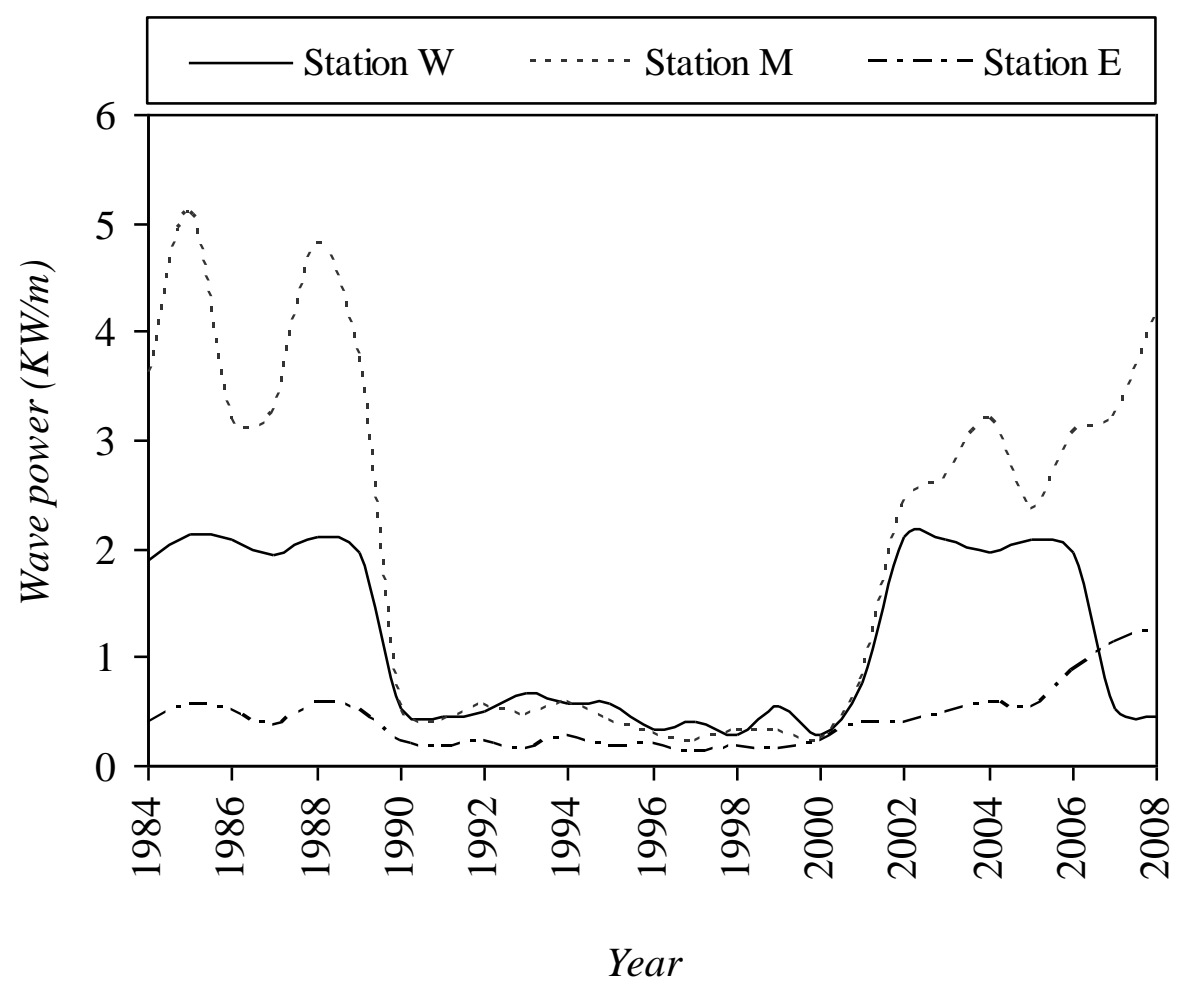

Fig. 6. Time series of the annual average of the wave power for three stations 


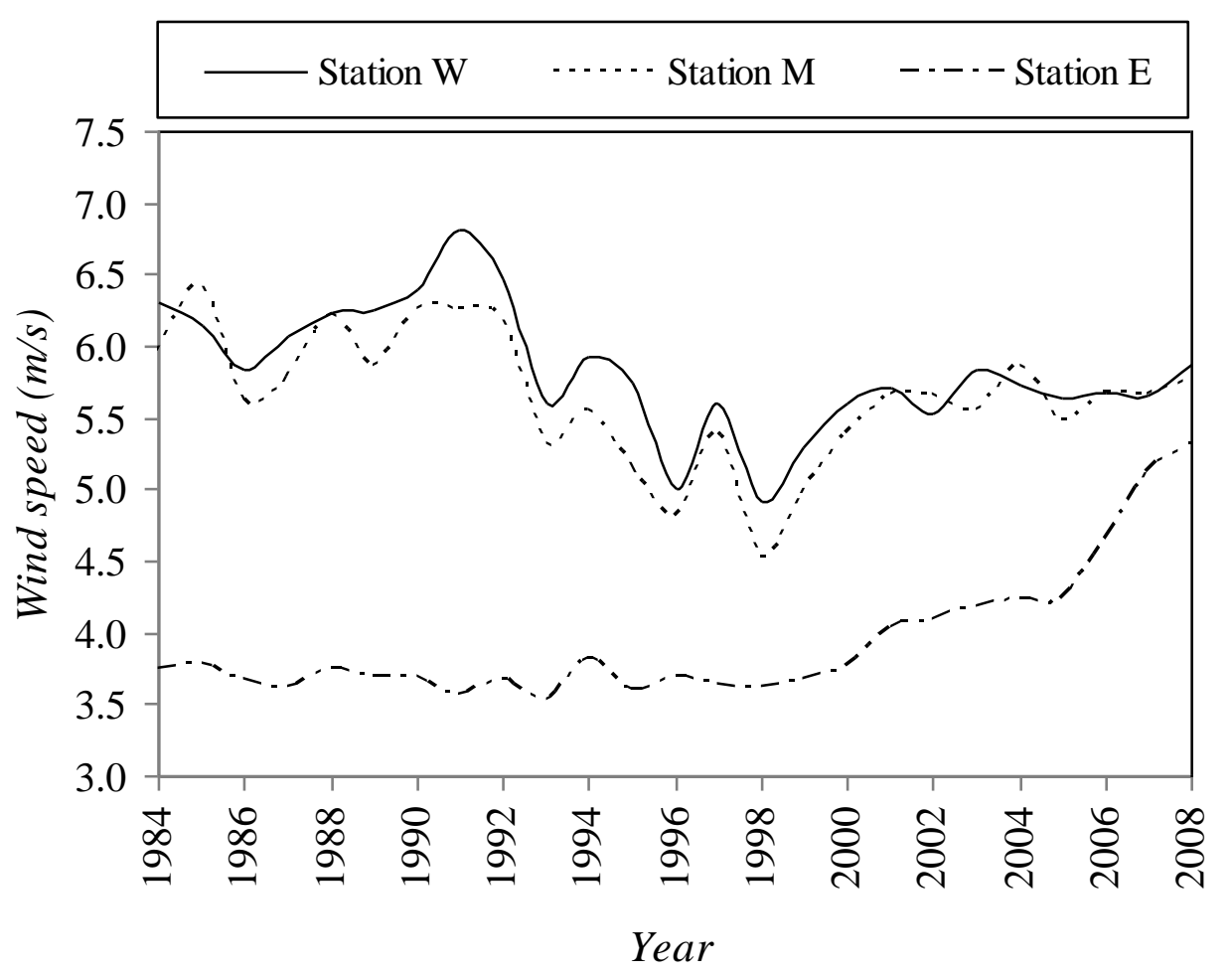

Fig. 7. Time series of the annual average of the ECMWF wind speed 


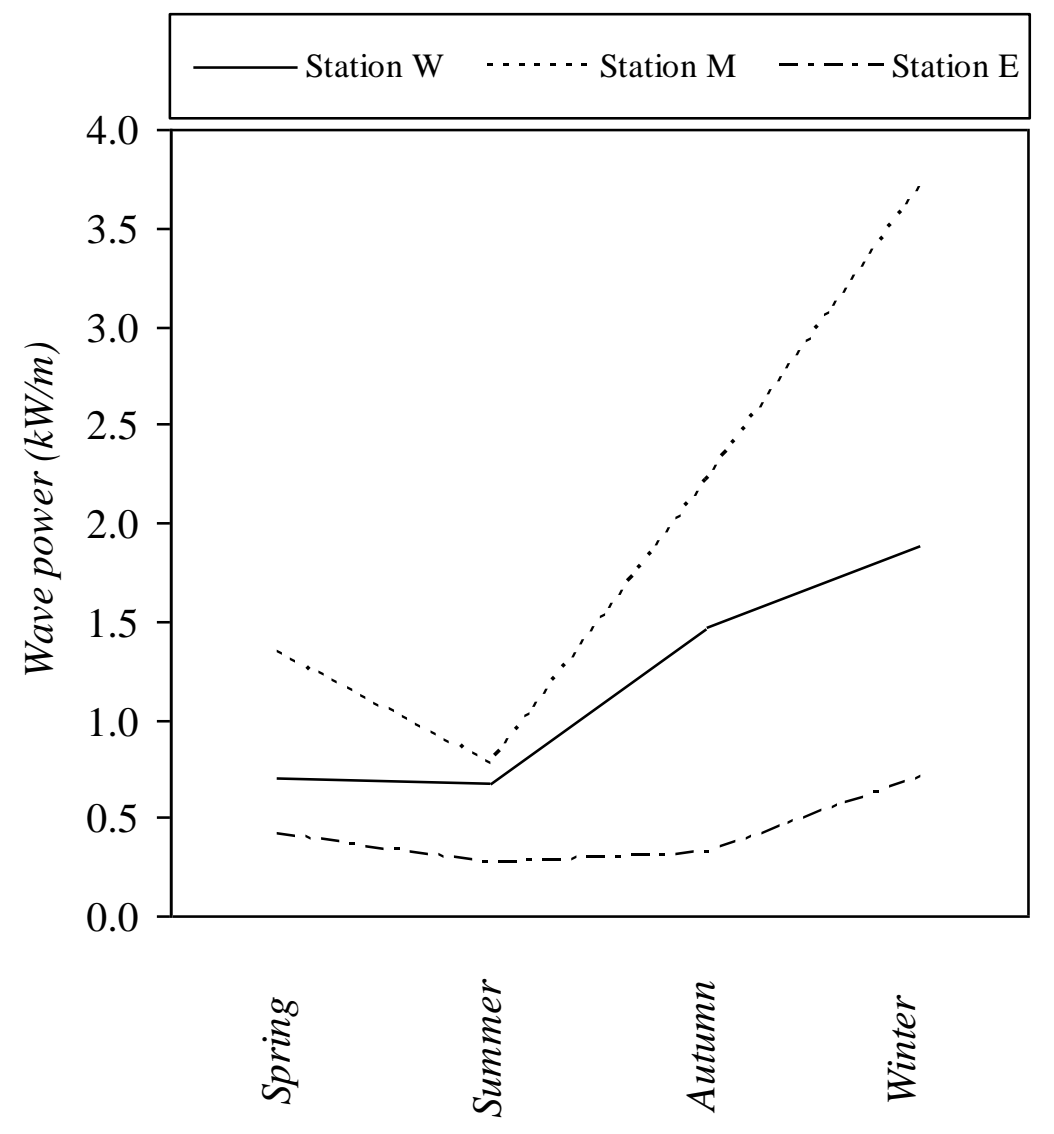

Fig. 8. Seasonal averages of wave power 


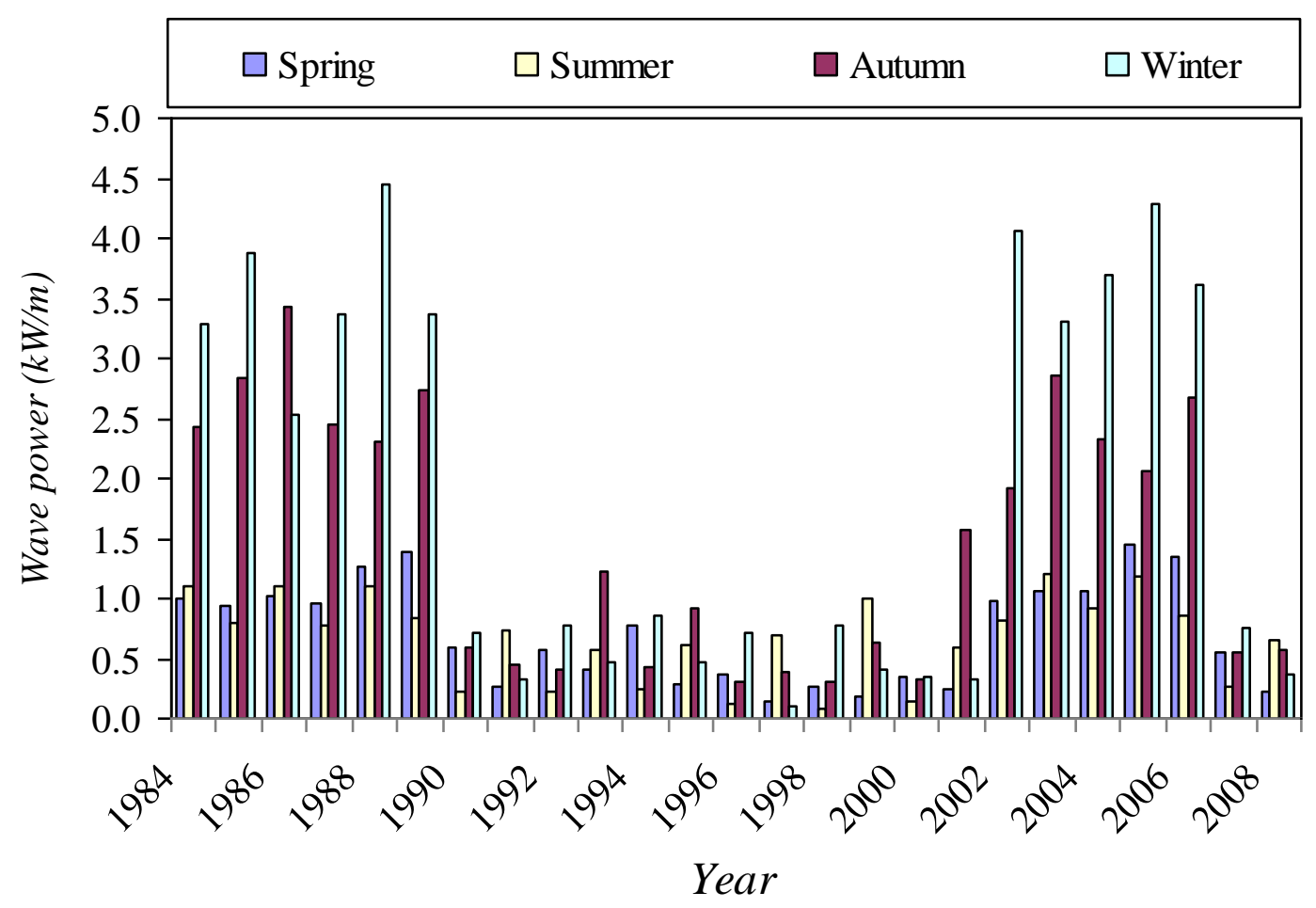

Fig. 9. Seasonal variation of wave power, station $\mathrm{W}$ 


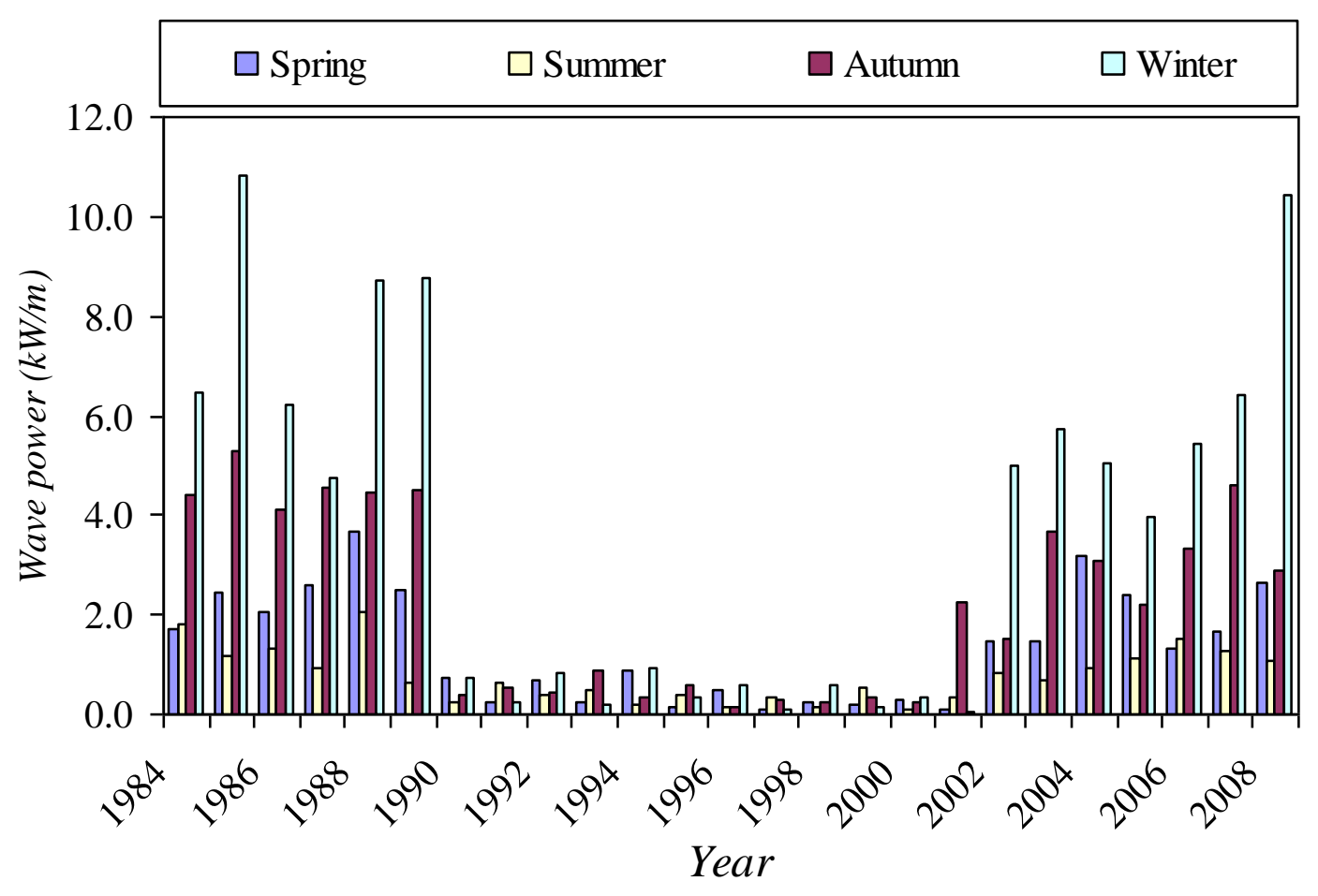

Fig. 10. Seasonal variation of wave power, station M 


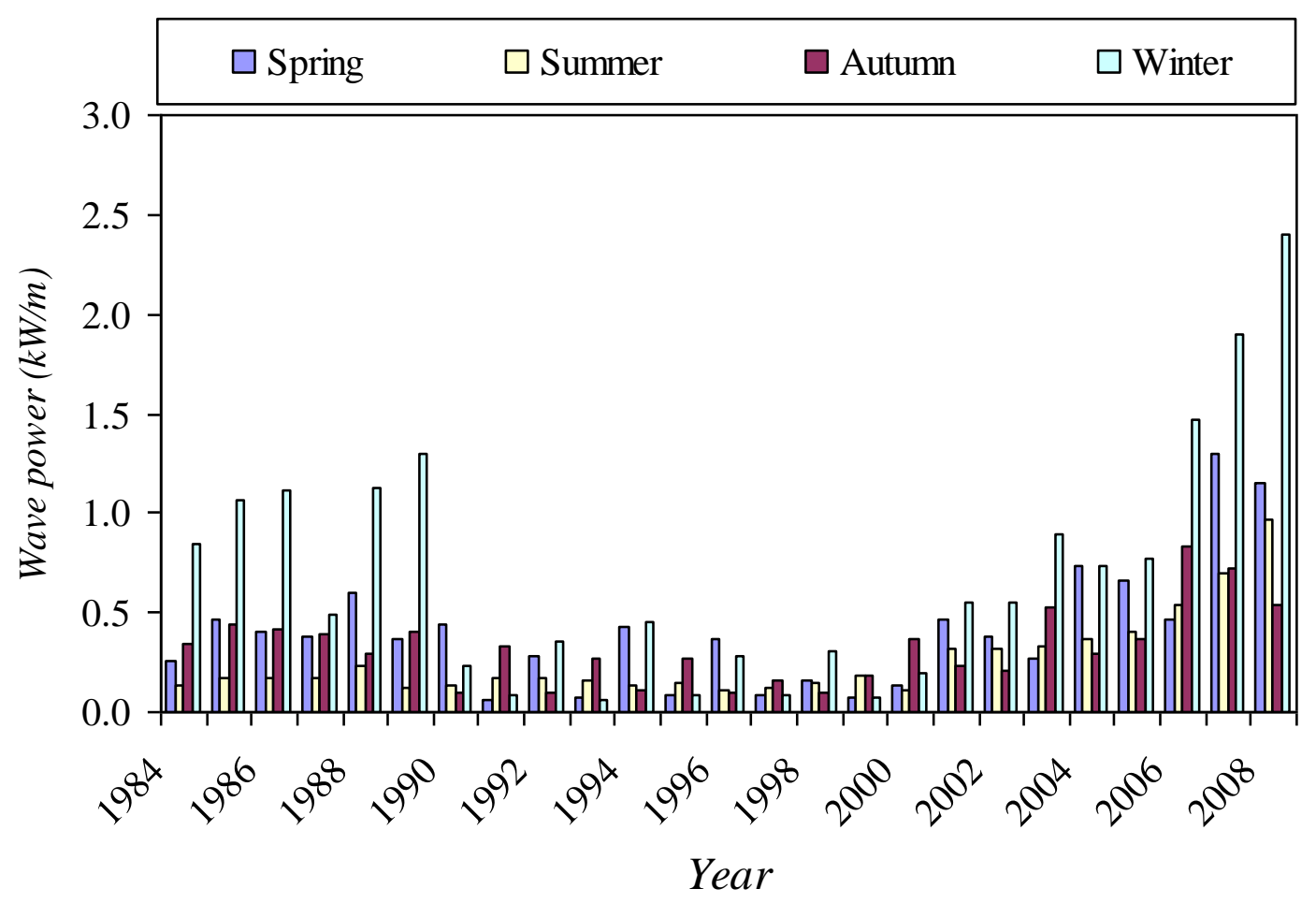

Fig. 11. Seasonal variation of wave power, station E 


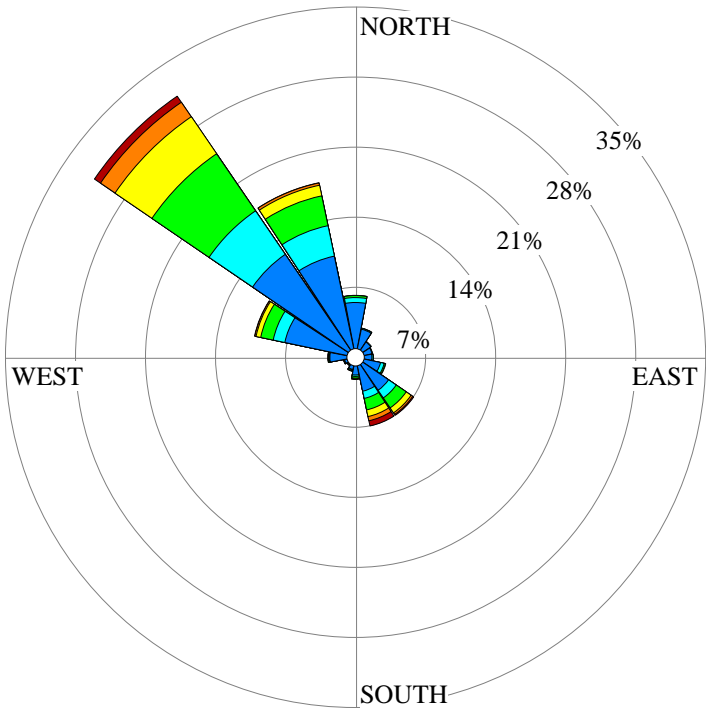

1984-1989

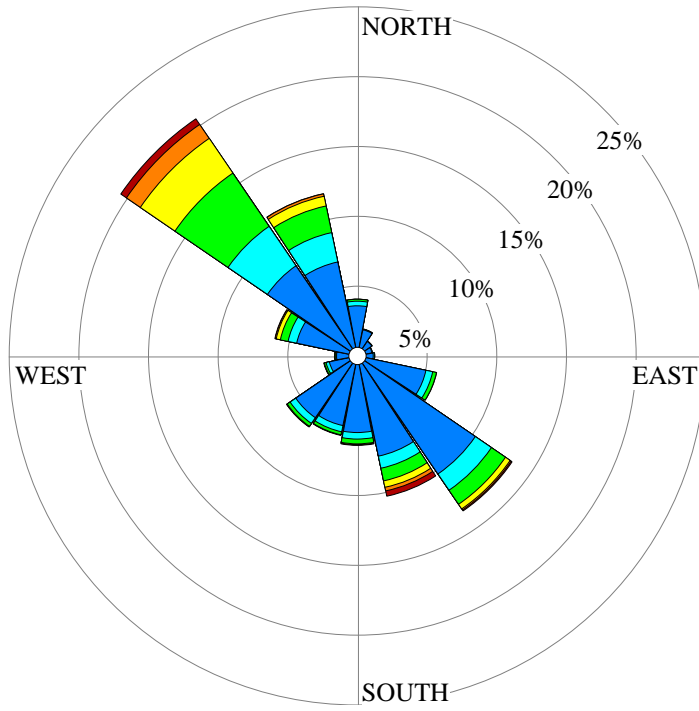

2001-2008

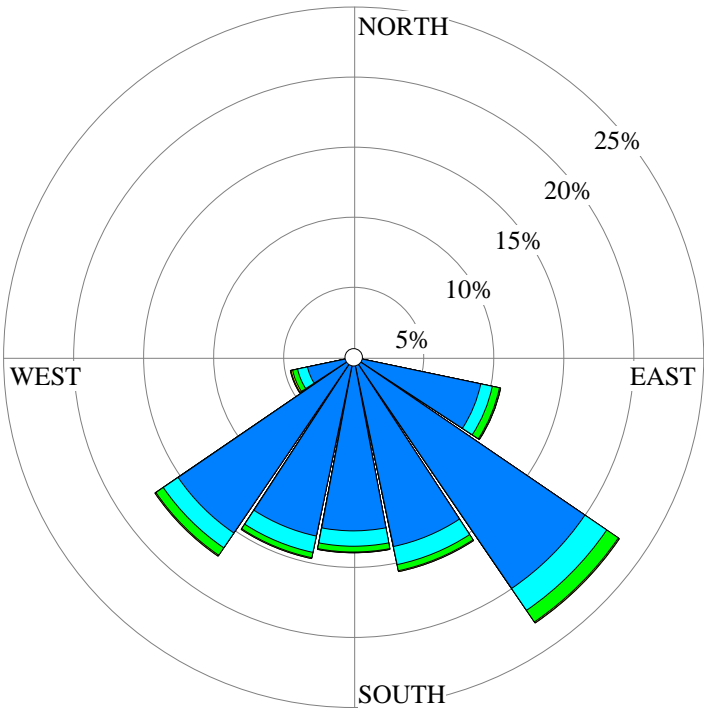

$1990-2000$

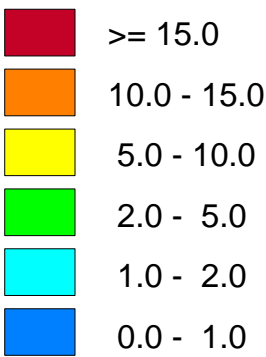

Calms: $0.00 \%$

Fig. 12. Power roses for three different periods, station $\mathrm{W}$ 


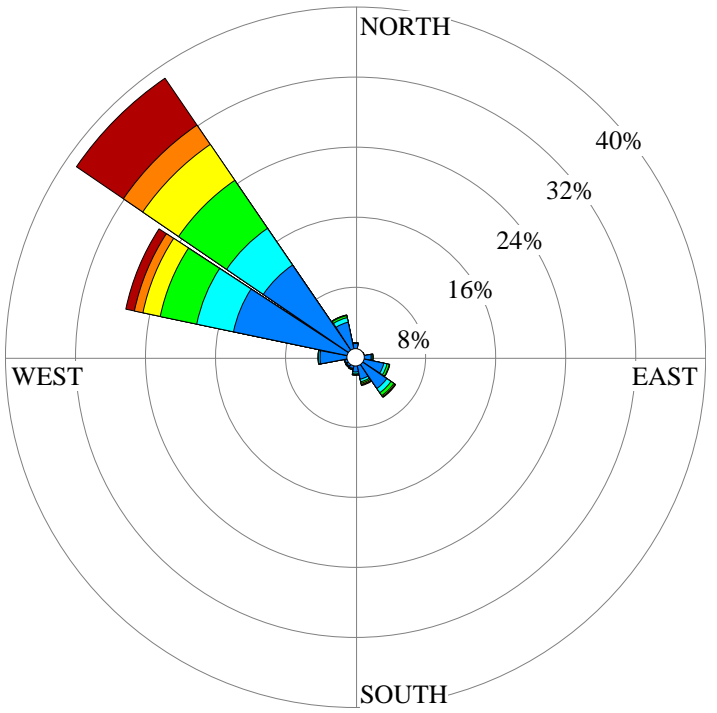

1984-1989

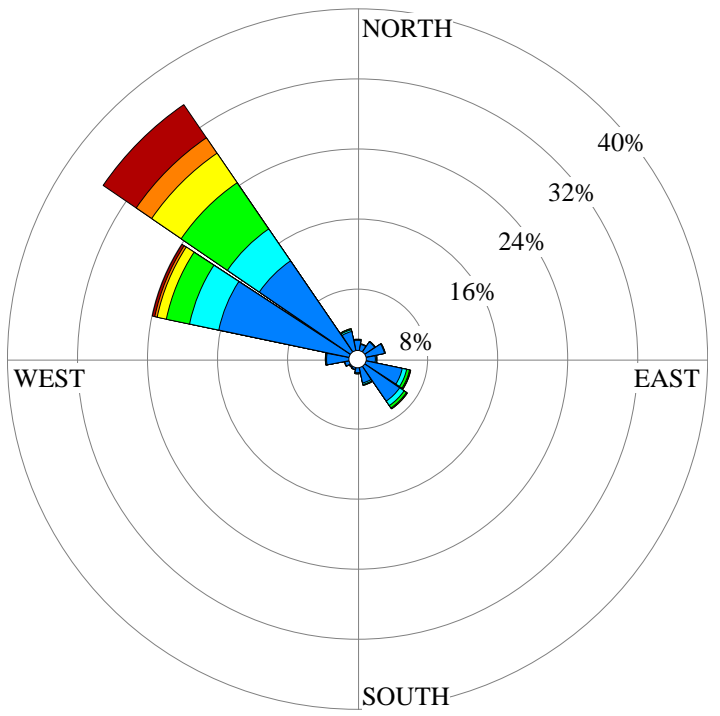

2001-2008

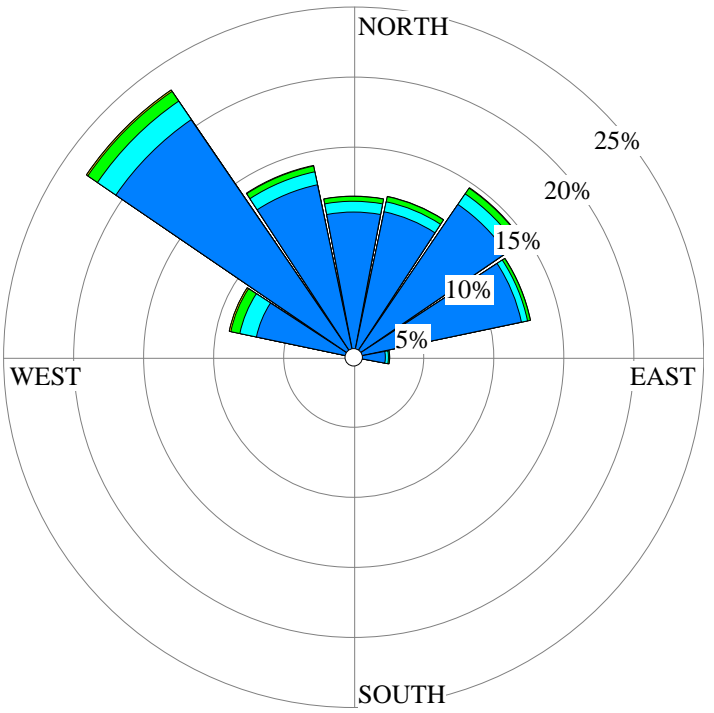

1990-2000

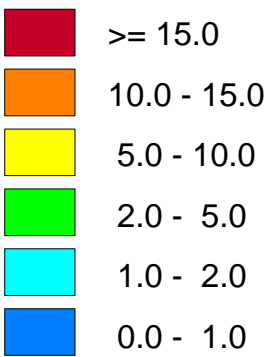

Calms: $0.00 \%$

Fig. 13. Power roses for three different periods, station M 


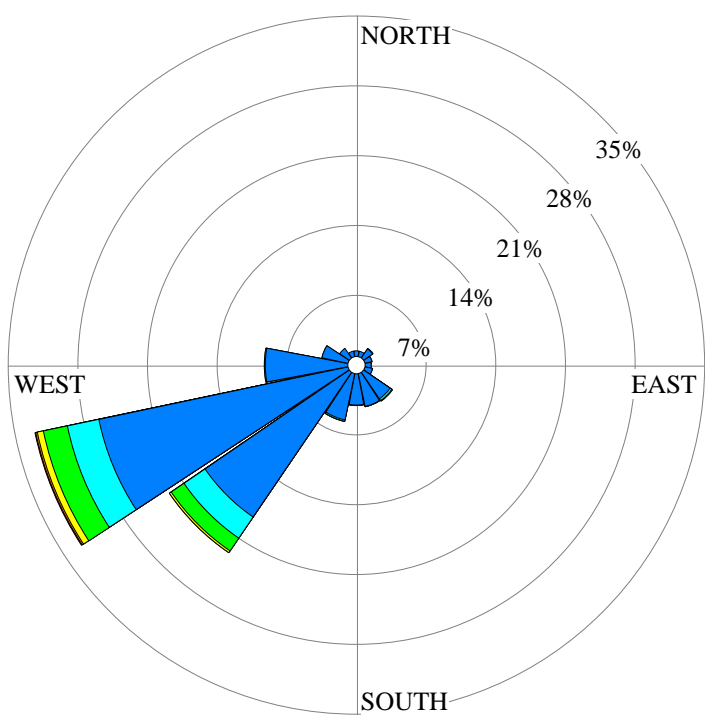

1984-1989

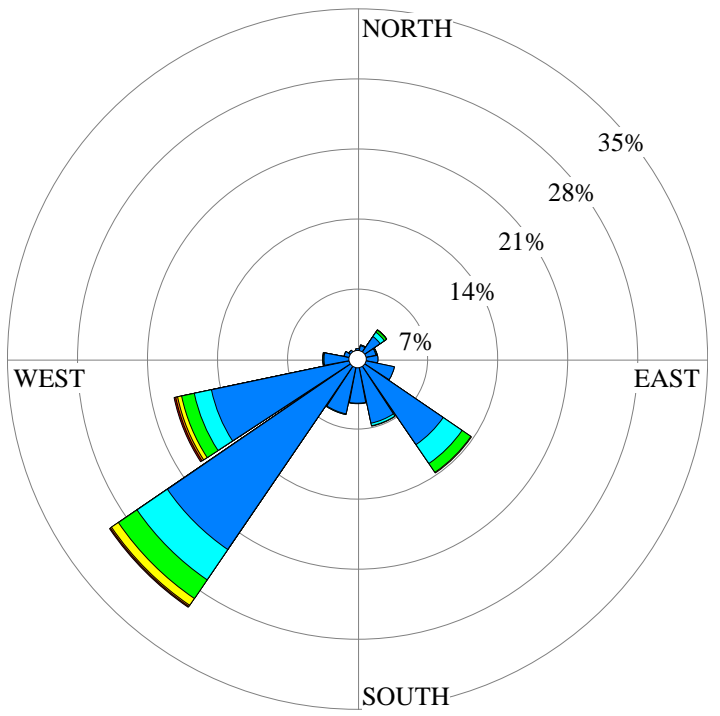

$2001-2008$

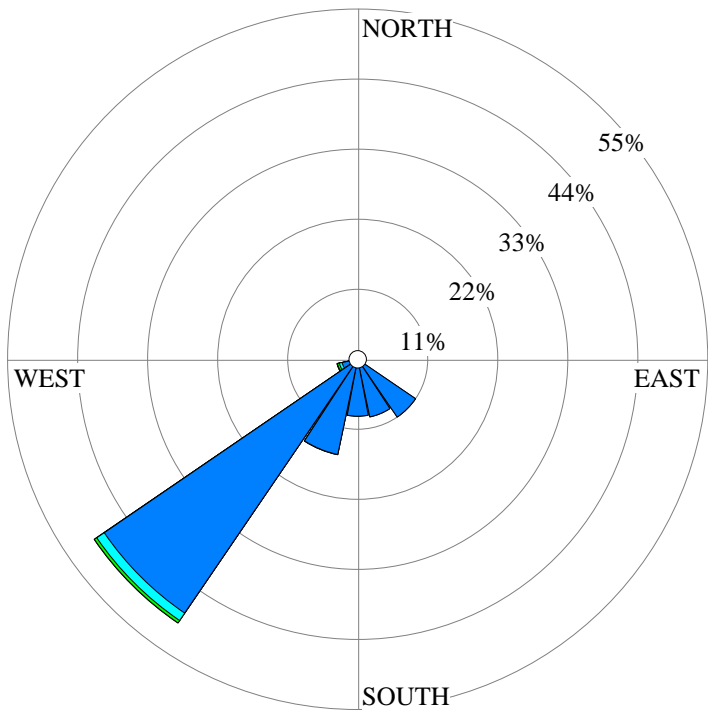

1990-2000

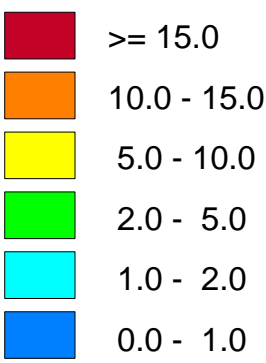

Calms: $0.00 \%$

Fig. 14. Power roses for three different periods, station E 
Table 1. Statistics of the measured wind and wave parameters in the calibration and verification periods

\begin{tabular}{cccccc}
\hline Period & Parameter & Minimum & Average & Maximum & $\begin{array}{c}\text { Standard } \\
\text { deviation }\end{array}$ \\
\hline \multirow{2}{*}{ Calibration } & $\begin{array}{c}\text { Significant wave } \\
\text { height (m) }\end{array}$ & 0.04 & 0.65 & 2.45 & 0.57 \\
\cline { 2 - 6 } & Peak period (s) & 2.20 & 4.06 & 6.62 & 1.16 \\
\hline Verification & $\begin{array}{c}\text { Significant wave } \\
\text { height (m) }\end{array}$ & 0.04 & 0.60 & 1.76 & 0.43 \\
\cline { 2 - 6 } & Peak period (s) & 1.80 & 3.72 & 5.89 & 0.98 \\
\hline Verification-2 & $\begin{array}{c}\text { Significant wave } \\
\text { height (m) }\end{array}$ & 0.08 & 0.53 & 1.99 & 0.42 \\
\cline { 2 - 6 } & Peak period (s) & 2.34 & 4.70 & 8.20 & 1.18 \\
\hline
\end{tabular}


Table 2. Error indices, calibration and verification periods

\begin{tabular}{|c|c|c|c|c|}
\hline & Error index & $H^{2} T$ & $H_{s}$ & $T_{p}$ \\
\hline \multirow{3}{*}{ 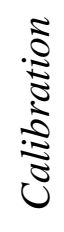 } & Bias & -0.039 & 0.011 & -0.153 \\
\hline & $C C$ & 0.888 & 0.927 & 0.891 \\
\hline & $R M S E$ & 3.621 & 0.220 & 0.846 \\
\hline \multirow{3}{*}{ 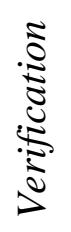 } & Bias & -0.53 & 0.002 & -0.013 \\
\hline & $C C$ & 0.78 & 0.856 & 0.788 \\
\hline & $R M S E$ & 2.35 & 0.230 & 0.676 \\
\hline \multirow{3}{*}{ 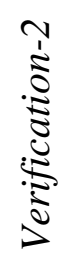 } & Bias & 0.650 & 0.088 & -0.704 \\
\hline & $C C$ & 0.811 & 0.867 & 0.616 \\
\hline & $R M S E$ & 3.094 & 0.244 & 1.372 \\
\hline
\end{tabular}


Table 3. Location and depth of selected stations

\begin{tabular}{cccc}
\hline Station & Longitude $\left({ }^{\circ} \mathrm{E}\right)$ & Latitude $\left({ }^{\circ} \mathrm{N}\right)$ & Depth $(\mathrm{m})$ \\
\hline $\mathrm{W}$ & 49.5 & 29.3 & 30 \\
$\mathrm{M}$ & 52.5 & 26.7 & 76 \\
$\mathrm{E}$ & 56.3 & 26.7 & 71 \\
\hline
\end{tabular}


Table 4. Wave power distribution of station M, 1984 to 1989

\begin{tabular}{cccccccc}
\hline \multirow{2}{*}{ Direction } & \multicolumn{7}{c}{ Wave power $(\mathrm{kW} / \mathrm{m})$} \\
\cline { 2 - 7 } & $0-1$ & $1-2$ & $2-5$ & $5-10$ & $10-15$ & $>=15$ & Total \\
\hline N & 4.05 & 0.17 & 0.04 & 0.02 & 0.00 & 0.01 & 4.29 \\
N-NE & 1.24 & 0.06 & 0.03 & 0.00 & 0.01 & 0.00 & 1.35 \\
NE & 1.24 & 0.08 & 0.06 & 0.01 & 0.01 & 0.00 & 1.40 \\
E-NE & 1.31 & 0.09 & 0.06 & 0.01 & 0.00 & 0.01 & 1.47 \\
E & 1.69 & 0.21 & 0.06 & 0.06 & 0.03 & 0.01 & 2.05 \\
E-SE & 2.57 & 0.30 & 0.17 & 0.11 & 0.07 & 0.09 & 3.30 \\
SE & 4.31 & 0.59 & 0.40 & 0.14 & 0.04 & 0.07 & 5.55 \\
S-SE & 3.30 & 0.35 & 0.28 & 0.04 & 0.02 & 0.00 & 3.99 \\
S & 1.78 & 0.08 & 0.11 & 0.03 & 0.01 & 0.00 & 2.01 \\
S-SW & 0.98 & 0.02 & 0.02 & 0.02 & 0.00 & 0.00 & 1.03 \\
SW & 0.88 & 0.02 & 0.00 & 0.00 & 0.00 & 0.00 & 0.90 \\
W-SW & 0.78 & 0.01 & 0.01 & 0.00 & 0.00 & 0.00 & 0.80 \\
W & 1.57 & 0.08 & 0.02 & 0.01 & 0.00 & 0.00 & 1.68 \\
W-NW & 4.08 & 0.53 & 0.25 & 0.06 & 0.01 & 0.01 & 4.93 \\
NW & 12.72 & 5.06 & 6.62 & 4.95 & 2.67 & 6.47 & 38.49 \\
N-NW & 14.22 & 4.29 & 4.24 & 2.02 & 0.99 & 1.00 & 26.76 \\
Sub-Total: & 56.72 & 11.94 & 12.36 & 7.47 & 3.85 & 7.66 & 100.00 \\
\hline
\end{tabular}


Table 5. Wave power distribution of station M, 1990 to 2000

\begin{tabular}{cccccccc}
\hline \multirow{2}{*}{ Direction } & \multicolumn{7}{c}{ Wave power $(\mathrm{kW} / \mathrm{m})$} \\
\cline { 2 - 8 } & $0-1$ & $1-2$ & $2-5$ & $5-10$ & $10-15$ & $>=15$ & Total \\
\hline N & 0.10 & 0.06 & 0.06 & 0.01 & 0.00 & 0.00 & 0.23 \\
N-NE & 0.00 & 0.00 & 0.00 & 0.00 & 0.00 & 0.00 & 0.00 \\
NE & 0.00 & 0.00 & 0.00 & 0.00 & 0.00 & 0.00 & 0.00 \\
E-NE & 0.00 & 0.00 & 0.00 & 0.00 & 0.00 & 0.00 & 0.00 \\
E & 0.00 & 0.00 & 0.00 & 0.00 & 0.00 & 0.00 & 0.00 \\
E-SE & 0.00 & 0.00 & 0.00 & 0.00 & 0.00 & 0.00 & 0.00 \\
SE & 0.02 & 0.00 & 0.00 & 0.00 & 0.00 & 0.00 & 0.02 \\
S-SE & 0.40 & 0.03 & 0.00 & 0.00 & 0.00 & 0.00 & 0.43 \\
S & 2.26 & 0.22 & 0.08 & 0.01 & 0.00 & 0.00 & 2.57 \\
S-SW & 12.20 & 0.45 & 0.21 & 0.01 & 0.00 & 0.00 & 12.88 \\
SW & 13.18 & 0.92 & 0.49 & 0.04 & 0.00 & 0.00 & 14.63 \\
W-SW & 10.59 & 0.73 & 0.37 & 0.02 & 0.00 & 0.00 & 11.70 \\
W & 10.34 & 0.77 & 0.35 & 0.01 & 0.00 & 0.00 & 11.47 \\
W-NW & 12.55 & 0.94 & 0.43 & 0.04 & 0.00 & 0.00 & 13.96 \\
NW & 20.49 & 1.59 & 0.84 & 0.11 & 0.00 & 0.00 & 23.04 \\
N-NW & 7.08 & 1.20 & 0.67 & 0.11 & 0.00 & 0.00 & 9.06 \\
Sub-Total: & 89.21 & 6.91 & 3.51 & 0.36 & 0.01 & 0.00 & 100.00 \\
\hline
\end{tabular}


Table 6. Wave power distribution of station M, 2001 to 2008

\begin{tabular}{cccccccc}
\hline \multirow{2}{*}{ Direction } & \multicolumn{7}{c}{ Wave power $(\mathrm{kW} / \mathrm{m})$} \\
\cline { 2 - 7 } & $0-1$ & $1-2$ & $2-5$ & $5-10$ & $10-15$ & $>=15$ & Total \\
\hline N & 3.54 & 0.06 & 0.04 & 0.02 & 0.00 & 0.00 & 3.68 \\
N-NE & 1.48 & 0.04 & 0.03 & 0.00 & 0.00 & 0.00 & 1.55 \\
NE & 1.12 & 0.05 & 0.01 & 0.00 & 0.00 & 0.00 & 1.18 \\
E-NE & 1.20 & 0.05 & 0.02 & 0.00 & 0.00 & 0.00 & 1.27 \\
E & 1.56 & 0.07 & 0.04 & 0.00 & 0.00 & 0.00 & 1.69 \\
E-SE & 2.79 & 0.17 & 0.09 & 0.02 & 0.00 & 0.01 & 3.07 \\
SE & 5.81 & 0.61 & 0.34 & 0.08 & 0.02 & 0.02 & 6.88 \\
S-SE & 5.22 & 0.52 & 0.32 & 0.09 & 0.05 & 0.01 & 6.20 \\
S & 2.03 & 0.13 & 0.05 & 0.01 & 0.00 & 0.00 & 2.22 \\
S-SW & 3.14 & 0.07 & 0.01 & 0.00 & 0.00 & 0.00 & 3.22 \\
SW & 2.36 & 0.06 & 0.02 & 0.00 & 0.00 & 0.00 & 2.45 \\
W-SW & 1.71 & 0.06 & 0.02 & 0.00 & 0.00 & 0.00 & 1.79 \\
W & 2.15 & 0.09 & 0.03 & 0.00 & 0.00 & 0.00 & 2.28 \\
W-NW & 3.22 & 0.19 & 0.11 & 0.02 & 0.00 & 0.00 & 3.54 \\
NW & 13.55 & 4.40 & 6.38 & 4.07 & 2.14 & 4.55 & 35.09 \\
N-NW & 16.16 & 3.40 & 2.71 & 1.06 & 0.29 & 0.28 & 23.91 \\
Sub-Total: & 67.05 & 9.98 & 10.22 & 5.37 & 2.51 & 4.88 & 100.00 \\
\hline
\end{tabular}

